\title{
Trends and Profile of Permanent Pacemaker Implantation in Nepal. Experience From Tertiary Cardiac Center (SGNHC) From 2001 to 2020.
}

\author{
Murari Dhungana1, Kunjang Sherpa', Roshan Raut', Surakchhya Joshi', Prashant Bajracharya', \\ Mukunda Sharma ${ }^{2}$, Man Bahadur K.C ${ }^{2}$, Dipanker Prajapati ${ }^{1}$, Santosh Yadav', Nripesh Adhikari', \\ Mandita Chamlagain', Subhekchhya Niraula', Chandra Mani Adhikari', Sujeeb Rajbhandari'.
}

${ }^{1}$ Department of cardiology, Shahid Gangalal National Heart Centre.

${ }^{2}$ Department of cardiology, Hospital for Advance Medicine and Surgery.

\section{Corresponding Author:}

Murari Dhungana

Shahid Gangalal National Heart Centre, Bansbari, Kathmandu, Nepal.

E-mail: murarid@yahoo.com

ORCID ID: https://orcid.org/0000-0002-5963-1101

Submitted date: $9^{\text {th }}$ January 2021

Accepted date: $8^{\text {th }}$ February 2021

Cite this article as: Dhungana M, Sherpa K, Raut R, et al. Trends and Profile of Permanent Pacemaker Implantation in Nepal. Experience From Tertiary Cardiac Center (SGNHC) From 2001 to 2020. Nepalese Heart Journal 2021; Vol 18 (1): 29-32.

\section{Abstract}

Background and Aims: The number of pacemaker implantation is increasing at various centres of Nepal with increase in cardiac services. However, there are few data available regarding the pacemaker implantation in Nepal. This study intend to focus and study trends and profile of permanent pacemaker implantation (PPI) of 19 years experience at the referral tertiary cardiac center which will reflect intended objective of this study.

Methods: This was a retrospective cross sectional study done at Shahid Gangalal National Heart Centre (SGNHC). The data of the patient who underwent PPI from 2001 November to 2020 August were reviewed. Patients data including age, sex, indication for pacing, mode of pacing, type of pacemaker implanted, implantation parameters such as lead impedence and threshold were recorded and analyzed.

Results: A total of 3631 pacemaker implantation were performed at SGNHC from 2001 November to 2020 August. Among the total patients, $59.4 \%$ were male with mean age of $65.2 \pm 15.2$ years. The most common indication was degenerative complete heart block $(74.8 \%)$. Sick sinus syndrome $(8.2 \%)$ was the second most common indication of pacing. The single chamber were implanted in $93.3 \%$ cases and dual chamber in $6.7 \%$ cases. VVIR was the most common mode of implantation in $93.1 \%$ cases, followed by DDDR (6.7\%). AAIR ( $0.1 \%)$ and VDD in $0.1 \%$ cases. The total number of pacemaker implanted yearly in SGNHC has increased since the early year of implantation. During the early years most of the pacemakers were Single chamber (VVI) pacemaker and the implantation of dual chamber pacemaker increased gradually from year 2010 onwards. After the year 2010 the implantation of dual chamber pacemaker has increased significantly compared to prior to 2010 $(p=0.001)$. There were no gender differences in use of single chamber and dual chamber implantation during this period. $(p v a l u e=$ 0.489). The dual chamber were implanted mostly in age group less than 65 year compared to more than 65 years $(\mathrm{P}$ value $=0.001)$. Conclusion: There is gradual increase in the number of pacemaker implantation yearly at SGNHC and since 2010 there is also increase in number of dual chamber pacemaker implantation though the single chamber pacemaker outnumbered the dual chamber implantation.

Keywords: Nepal; Permanent Pacemaker.

DOl: https://orcid.org/10.3126/njh.v18i1.36778

\section{Introduction}

Pacemaker implantation is the treatment of choice in electrophysiological conditions like sinus node disease, atrioventricular (AV) node disease, which cause or may cause either prognostically or symptomatically significant bradycardia.

A worldwide survey undertaken for Pacemaker implantation in

(a) Nepalese Heart Journal. Nepalese Heart Journal retain copyright and works is simultaneously licensed under Creative Commons Attribution License CC - By 4.0 that allows others to share the work with an acknowledge of the work's authorship and initial publication in this journal 
calendar year 2009 and compared to a similar survey conducted in 2005 showed, virtually all countries showed increases in implant numbers over the 4 years between surveys. High-degree atrioventricular block and sick sinus syndrome remain the major indications for implantation of a cardiac pacemaker. There remains a high percentage of VVI (R) pacing in the developing countries, although compared to the 2005 survey, virtually all countries had increased the percentage of DDDR implants. ${ }^{2}$

There are few studies and reports have been published regarding clinical profile, short term outcome, experiences in pacemaker implantation in different center in our part of the world. ${ }^{3-7}$

This study intended focusing on permanent pacemaker implantation (PPI) of 19 years data at the referral tertiary cardiac center which will highlight and reflect a clear picture of the trends and profile of PPI implantation in Nepal.

\section{Methods}

This is a single centre retrospective observational study which was performed in the Department of Cardiology, Shahid Gangalal National Heart Centre (SGNHC), Bansbari, Kathmandu. All the patient's data were collected from the hospital records after having permission of institutional review committee. Patients who underwent PPI from 2001 November (first case) to 2020 august 31 were included in the study. Patients data including age, sex, indication for pacing, mode of pacing, type of pacemaker implanted, implantation parameters such as lead impedence and threshold were searched in the records. All data was entered into an electronic spread sheet (Microsoft Excel, Redmond) and The Statistical analysis was done using the SPSS Version 20 software (SPSS INC, Chicago, III). Categorical variables were presented as proportions or percentages. After processing of all available information, statistical analysis of their significance was done. All parametric values were expressed as mean \& nonparametric values were expressed in percentage (\%). The significance of difference between two groups was determined by using unpaired students't test, Pearson's chi-square test and ' $z$ ' test where applicable. 'P' value of less than 0.05 was considered to be significant.

\section{Results}

During the 19 years experiences from November 2001 to August 2020, 3631 pacemaker implanted in SGNHC. The mean age group of the study population was $65.2 \pm 15.2$ years with $59.5 \%$ being Male patients and $40.5 \%$, female patients. The single chamber was implanted in $93.3 \%$ cases and dual chamber in $6.7 \%$ cases. VVIR was the most common mode of implantation in $93.1 \%$ cases, followed by DDDR $(6.7 \%)$, AAIR $(0.1 \%)$ and VDD in $0.1 \%$ cases as shown in table 1 .

Table 1: Baseline characteristics of the permanent pacemaker implantation patients (2001-2020).

\begin{tabular}{ll} 
Variable & Frequency \\
\hline Age $($ Mean \pm SD) & $65.2 \pm 15.2$ years \\
\hline Sex $(\mathrm{N} / \%)$ & \\
\hline Male & $2159(59.5 \%)$ \\
Female & $1472(40.5 \%)$ \\
\hline Type of Permanent Pacemaker $(\mathrm{N} / \%)$ & \\
\hline Single Chamber & $3389(93.3 \%)$
\end{tabular}

\begin{tabular}{ll} 
Dual Chamber & $242(6.7 \%)$ \\
\hline Mode of Permanent Pacemaker (N/\%) & \\
\hline VVIR & $3379(93.1 \%)$ \\
DDDR & $242(6.7 \%)$ \\
AAIR & $5(0.1 \%)$ \\
VDD & $3(0.1)$
\end{tabular}

Degenerative complete heart block (CHB) was the most common indication of pacemaker implantation in $74.8 \%$ cases followed by sinus node disease in $8.2 \%$ cases. The other indication of pacemaker implantation are shown in table 2. Pulse generator replacement was done in $7.1 \%$ cases and Redo PPI were done in $2.5 \%$ cases.

Table 2: Indication of permanent pacemaker implantation.

\begin{tabular}{|l|l|}
\hline Indication & Number (\%) \\
\hline Degenerative CHB & $2716(74.8)$ \\
\hline Sick Sinus Syndrome & $299(8.2)$ \\
\hline 2:1 AV Block & $103(2.8)$ \\
\hline Congenital CHB & $80(2.2)$ \\
\hline Bifascicular Block & $30(0.8)$ \\
\hline High Grade AV Block & $29(0.8)$ \\
\hline Trifascicular Block & $16(0.4)$ \\
\hline Post Operative CHB & $8(0.2)$ \\
\hline Pulse Generator Replacement & $258(7.1)$ \\
\hline Redo PPI & $92(2.5)$ \\
\hline
\end{tabular}

The total number of pacemaker implanted yearly in SGNHC has increased since the early year of implantation as shown in figure 1 . During the early years most of the pacemakers were single chamber (VVI) pacemaker and the implantation of dual chamber pacemaker increased gradually from year 2010 onwards as shown in figure 2 .

Figure 1: Trends of pacemaker implantation from November 2001 to August 2020.

\section{Trends of pacemaker implantation from November 2001 to August 2020}

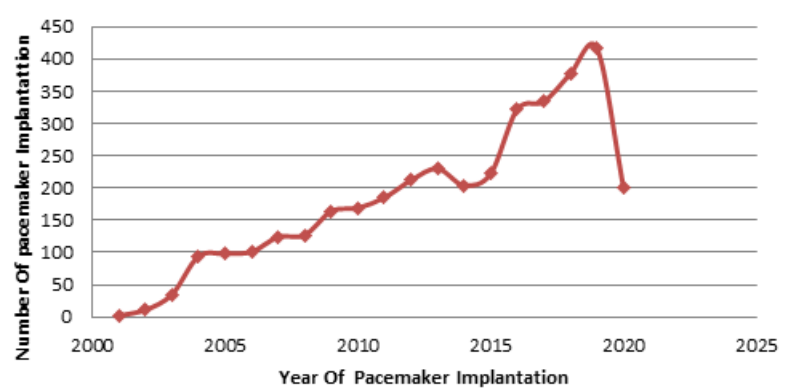


Figure 2: Trends of single vs. dual chamber pacemaker implantation from November 2001 to August 2020.

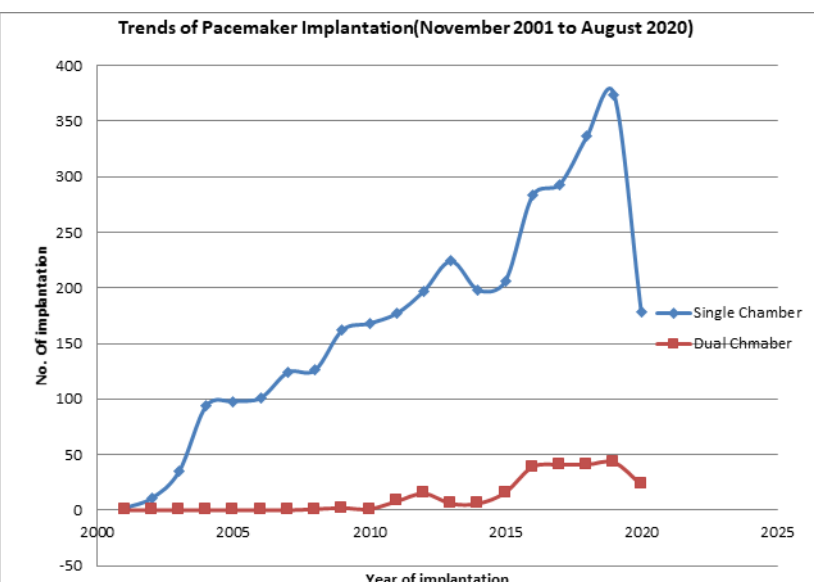

After the year 2010, the implantation of dual chamber pacemaker has increased significantly compared to prior to 2010 ( $\mathrm{p}=0.001)$. There were no gender differences in use of single chamber and dual chamber implantation during this period. ( $\mathrm{p}$ value $=0.489$ ). The dual chamber were implanted mostly in age group less than 65 year compared to more than 65 years $(\mathrm{P}$ value $=0.001)$ as shown in Table 3 .

Table 3: Comparison of single vs. dual chamber pacemaker as per gender, age and year of implantation:

\begin{tabular}{|llll} 
Variable & $\begin{array}{l}\text { Single } \\
\text { Chamber }\end{array}$ & $\begin{array}{l}\text { Dual } \\
\text { Chamber }\end{array}$ & P value \\
\hline Male & 2010 & 149 & $<0.489$ \\
Female & 1379 & 93 & \\
\hline Age $<65$ & 1449 & 170 & $<0.001$ \\
Age $>65$ & 1940 & 72 & \\
\hline Before 2010 & 923 & 4 & $<0.001$ \\
After 2010 & 2466 & 236 & \\
\hline
\end{tabular}

\section{Discussion}

Our study showed that trend in the implantation of pacemaker has increased gradually from year 2001 up to mid August 2020. In spite of the dual chamber pacemakers being more physiologic ones, the single chamber pacemaker implantation (in $93 \%$ cases) outnumbered dual chamber.

The trends in the use of more number of single chamber pacemakers as in our study is similar to the other study done at various cardiac centers of our country ${ }^{3-7}$ and India. ${ }^{8}$ However the trend of implantation of pacemaker in other developed countries at USA $^{9}$ and Australia ${ }^{10}$ have showed majority of their patients received dual chamber pacemaker. The probable reason behind the difference with less use of dual chamber may be due to its higher cost compared to single chamber. However after the year 2010 there was gradual increase in number of dual chamber implantation. The reason behind the increasing trend toward dual chamber implantation in the recent years could be because of increase in patient awareness and financial strength and increase in physician skill as well as number of physician implanting the device.

In this study, male patients were the predominant pacemaker recipient $(59.5 \%)$ in comparison to female patients $(40.6 \%)$ which were similar to a single centre study conducted in Northern Greece where $54 \%$ of patients were male $\mathrm{e}^{11}$ and also identical to the $11^{\text {th }}$ world survey for cardiac devices where male population was predominantly higher than the female ( $68 \%$ vs. $32 \%))^{2}$ The similar findings has been shown in various study done in our part of the country. ${ }^{3-7}$

The mean age of the study population was 65 years which were similar to the other study done at India with mean age of $60.5,{ }^{8}$ In Poland mean age of 63.5 years ${ }^{12}$ and similar to the other study done in our country. ${ }^{3-7}$ However in other registries and the $11^{\text {th }}$ world survey mean age ranged from 65 to 80 years in patients who underwent PPM implantation. ${ }^{2,13-17}$

The most common indication of pacing was found to be the degenerative complete heart block (74.8\%) and sick sinus syndrome the second most common $(8.2 \%)$. The reason might be the degenerative process that lead the disease in the aging population. The indications for permanent pacemaker implantation were similar to the study done in Indian population ${ }^{8}$ and other studies done in our coutry. ${ }^{3-7}$ In contrary, pacemaker registry of Netherlands showed sick sinus syndrome as the prime indicator $(42.3 \%)$ for pacemaker implantation followed by heart block $(38.9 \%)^{18}$ and Swedish pacemaker registry reported atrioventricular conduction disorders $(38 \%)$ as the commonest cause followed by sick sinus syndrome (34\%). ${ }^{14}$

The major limitation of the study was it was single centre study and was a retrospective study. However, since our center is the tertiary referral cardiac centre, the data represents the total context of Nepal as most patients are referred to our centre for the PPI implantation and may give the clear picture of the trends of PPI implantation our country.

\section{Conclusion}

There is gradual increase in the number of pacemaker implantation yearly at SGNHC and since 2010 there is also increase in number of dual chamber pacemaker implantation though the single chamber pacemaker outnumbered the dual chamber implantation.

\section{Source of Funding: None \\ Conflict of Interest: None}

\section{References}

1. Morgan JM. Basics of cardiac pacing: selection and mode choice. Heart. 2006;92(6):850-54. https://doi.org/10.1136/hrt.2005.076661

2. Mond H.G, Proclemer A. The $11^{\text {th }}$ world survey of cardiac pacing and implantable cardioverter -defibrillators: calendar year 2009-a World Society of Arrhythmia's project PacingClinElectrophysiol, 34 (2011)1013-1027. https://doi.org/10.1111/j.15408159.2011.03150.x

3. Khanal, J, Poudyal, R. R, Devkota, S, et al. Clinical Profile and Early Complications after Single and Dual Chamber Permanent Pacemaker Implantation at Manmohan Cardiothoracic Vascular and Transplant Centre, Kathmandu, Nepal. J Nepal Health Res Counc. 2015;13(30):138-43.

4. Monib A, Nepal R, Dhungana S, et al. Early outcome of permanent pacemaker implantation. Journal of Nobel Medical College, 2018; 7(2), 35-38.

https://doi.org/10.3126/jonmc.v7i2.22304 
5. Jha S, A.S, Pahari A. Cardiac pacing at TU Teaching HospitalChanging perspective. Journal of Institute of Medicine. 2007 Jan 21;20(1).

6. Khanal J, P.R, Devkota S, et al. Gender Differences in Selection of Permanent Pacemaker Implantation at Manmohan Cardiothoracic Vascular and Transplant Centre, Kathmandu, Nepal. Journal of Nobel Medical College. 2015 Sep 1; 4(1):15-20.

https://doi.org/10.3126/jonmc.v4i1.13299

7. Thapa S. Gajurel R. M. Paudel C. M, et al. Study of clinical profile and indications of Permanent Pacemaker Insertionin Nepali population presenting to tertiary care centre in Nepal. Nepalese Heart Journal 2019; Vol 16 (2), 47-52. https://doi.org/10.3126/njh.v16i2.26317

8. Kumar B, Prakash J, Kumari S, et al. Trends in Permanent Pacemaker Implantation in Indian Population: A Single Centre Experience Journal of Clinical and Diagnostic Research. 2018 Dec,Vol-12(12): OC10-OC12. https://doi.org/10.7860/JCDR/2018/37761.12371

9. Greenspon AJ, Patel JD, Lau E, et al. Trends in permanent pacemaker implantation in the United States from 1993 to 2009: increasing complexity of patients and procedures. Journal of the American College of Cardiology. 2012;60(16):1540-45.

https://doi.org/10.1016/j.jacc.2012.07.017

10. Gillam MH, P.N, Inacio MC, et al. Rehospitalizations for complications and mortality following pacemaker implantation: A retrospective cohort study in an older population. Clinical cardiology. 2018 Nov;41(11):1480. https://doi.org/10.1002/clc.23091

11. Styliadis IH, Mantziari AP, Gouzoumas NI, et al. Indications for permanent pacing and pacing mode prescription from 1989 to 2006. Experience of a single academic centre in Northern Greece. Hellenic J Cardiol. 2008;49:155-62.

12. Dêbski M, Ulman M, Z¥ Bek A, et al. Gender differences in dual-chamber pacemaker implantation indications and long- term outcomes. Acta Cardiologica. 2016;71(1):41-45. https://doi.org/10.1080/AC.71.1.3132096

13. Proclemer A, Ghidina M, Gregori D, et al. Trend of the main clinical characteristics and pacing modality in patients treated by pacemaker: data from the Italian Pacemaker Registry for the quinquennium 2003-07. Europace. 2009;12(2):202-09. https://doi.org/10.1093/europace/eup346

14. Gadler F, Valzania C, Linde C. Current use of implantable electrical devices in [10] Sweden: data from the Swedish pacemaker and implantable cardioverter-defibrillator registry. EP Europace. 2014;17(1):69-77.

https://doi.org/10.1093/europace/euu233

15. Tuppin P, Neumann A, Marijon E, et al. [11] Implantation and patient profiles for pacemakers and cardioverter-defibrillators in France (2008-2009). Archives of Cardiovascular Diseases. 2011;104(5):332-42.

https://doi.org/10.1016/j.acvd.2011.04.002

16. Uslan DZ, Tleyjeh IM, Baddour LM, et al. Temporal trends in permanent pacemaker implantation: a population-based study. American Heart Journal. 2008;155(5):896-903. https://doi.org/10.1016/j.ahj.2007.12.022

17. Samartín RC, Pérez ÓC, Jiménez MP. Spanish pacemaker registry. eleventh official report of the spanish society of cardiology working group on cardiac pacing (2013). Revista Española de Cardiología (English Edition). 2014;67(12):102438. https://doi.org/10.1016/j.rec.2014.08.004

18. Larsen P, Kerr A, Hood M, et al. Pacemaker use in New Zealand-data from the New Zealand implanted cardiac device registry (ANZACS-QI 15). Heart, Lung and Circulation. 2017;26(3):235-39. https://doi.org/10.1016/j.hlc.2016.06.1206

19. Proclemer A, Zecchin M, D'Onofrio A, et al. The pacemaker and implantable cardioverter-defibrillator registry of the italian association of arrhythmology and cardiac pacingannual report 2016. GiornaleItaliano Di Cardiologia (2006). 2018;19(2):119-31 